\title{
Highly selective and sensitive colorimetric chemosensor based on tricarboyanine for detection of $\mathrm{Ag}^{+}$in industrial wastewater
}

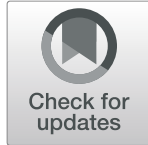

\author{
Xiaolong Zeng ${ }^{1,2}$, Xuezhao $\mathrm{Li}^{1}$ and Wen Sun ${ }^{1 *}$
}

\begin{abstract}
An efficient fluorescent probe 1 based on tricarbocyanine derivative was designed and synthesized, which can detect $\mathrm{Ag}^{+}$in real industrial wastewater. UV-Vis absorption and fluorescent emission spectra of probe 1 were carried out and indicated this probe can bind $\mathrm{Ag}^{+}$via complexation reaction, then leading to a remarkable color change from blue to light red. Furthermore, probe 1 showed high sensitive performance and excellent selectivity toward $\mathrm{Ag}^{+}$over other common metal ions in neutral $\mathrm{pH}$. The sensing mechanism was proposed and further confirmed by ${ }^{1} \mathrm{H} N \mathrm{NR}$, which demonstrate analyte-induced destruction of the $\pi$-electron system could be shorten by the disruption of the pull-push $\pi$-conjugation system in probe 1 . Moreover, a test strip was prepared by filter paper immersing in probe 1 solution, which further provide its potential application for trace $\mathrm{Ag}^{+}$detection in real industrial wastewater.
\end{abstract}

Keywords: Fluorescent chemosensor, Cyanine, Silver ion detection, Industrial wastewater

\section{Introduction}

Ag element and its derivative are extensively used in photography industry, electrical industry as well as pharmaceutical industry [1-3]. On the other hand, owing to the excellent antimicrobial activity, nowadays silver nanoparticles are also of great significance using in consumer product like leather goods. In recent years, researchers proposed a method for designing an antibacterial coating of leather, which first prevent from bacterial adhesion and subsequently kill and remove the attached bacterial from the coating surface of leather [4]. The green and in situ synthetic techinique of coating silver nanoparticles on leather was also well investigated [5]. Although Ag ion hold superior antibacterial effect, it may also cause toxicity towards mammalian cells [6]. The released Ag ion form industrial or laboratory wastewater to the environment has been estimated more than

\footnotetext{
* Correspondence: sunwen@dlut.edu.cn

${ }^{1}$ State Key Laboratory of Fine Chemicals, Dalian University of Technology, 2 Linggong Road, Hi-Tech Zone, Dalian 116024, China

Full list of author information is available at the end of the article
}

$2500 \mathrm{t}$ every year, of which most of them ran into wastewater treatment plants. However, there is still $80 \mathrm{t} \mathrm{Ag}$ ion released into surface waters [2]. Although the toxicity of Ag ion ranges from several orders of magnitude, strongly depend upon the type of compound and the medium in which it is found $[7,8]$. Long term exposure of $\mathrm{Ag}$ ion could still cause severe toxicity to animals and human beings [9-11]. Therefore, the development of $\mathrm{Ag}$ ion detection method in wastewater is emergently required.

There are several types of technologies to detect $\mathrm{Ag}$ ion [12-16]. Inductively coupled plasma atomic emission spectrometry (ICP-AES), inductively coupled plasma mass spectrometry (ICP-MS) [17], atomic absorption spectrometry (AAS) [18] etc. are easily available to detect $\mathrm{Ag}$ ion, but they are high-cost and time-consuming [19]. Therefore, a simple and rapid technology for detecting $\mathrm{Ag}$ ion is required. Recently, various molecules including metal-organic frameworks (MOFs), quantum dots (QDs) have been used to detect metal ions [20-23]. QDs receive considerable interest for sensing due to 
their high fluorescent quantum yield, good antiphotobleaching. MOFs are also promising materials since the unique host matrices with diverse functional species. However, QDs suffer limitations from the batchto-batch variation. It is also difficult to control the size and fluorescence performance of QDs, which may be the bottleneck to mass production. In addition, the practical use of MOFs has also been restricted because of their low selectivity, high construction cost and difficulty in reformation [24]. Therefore, it is necessary to exploit new chemical sensors with a controllable manner and good regeneration ability. Lately, fluorescent chemosensors can achieve these advantages and also provide realtime detection of various heavy metal ions like $\mathrm{Cu}^{2+}$ [25-27], $\mathrm{Cd}^{2+}$ [28-30], $\mathrm{Fe}^{3+}[31,32], \mathrm{Cr}^{3+}$ [33-35], $\mathrm{Pb}^{2+}$ [36] and $\mathrm{Zn}^{2+}[37-39]$. On the basis of ion-induced change of fluorescence, fluorescent chemosensors have been widely developed owing to their simplicity and high detection limit [40]. Most of fluorogenic ion chemosensor are composed of an ion recognition component which decorated with a signal fluorophore. When analyte interacts with fluorophore, the change of fluorescence signal of fluorophore could be observed with the appearance of quenching, enhancement or shift in the fluorescence maxima [41].

Chemosensors derived from rosamine [42], pyrene [43, 44], porphyrin [45] and carboyanine [46] have been made for $\mathrm{Ag}^{+}$detection. However, the excitation and emission wavelength of these chemosensors locate in the short wavelength region, most of them were lack of high selectivity or show no color changes [47]. Thus, it is also extremely valuable to develop novel $\mathrm{Ag}^{+}$fluorescent chemosensor.

Among the various fluorophore chemosensors, heptamethine cyanine $(\mathrm{Cy} 7)$ dyes have attracted great interest because of their favorable optical properties. $\mathrm{Cy} 7$ dyes also feature high absorption coefficient and high fluorescence quantum yield $[46,48]$. What's more, the excitation and emission wavelength of $\mathrm{Cy} 7$ dyes locate in red or near infrared region, which is the key point for decreasing background emissions, reducing scattering and also meaningful for metal ion detection [41].

In this study, we reported a new $\mathrm{Cy} 7$ derivative probe 1 bearing an alkynyl piperazine unit as an Ag ion capture. Probe 1 exhibits strong fluorescence due to $\mathrm{Cy} 7$ fluorophore. Among the different kind of examined metal ion, probe 1 exhibits a selective and unique color change with $\mathrm{Ag}$ ion at different $\mathrm{pH}$, owing to the coordination mechanism between silver ion and nitrogen atoms as well as alkynyl group.

\section{Experimental methods}

\subsection{Materials and reagents}

Phosphorus oxychloride (99\%), cyclohexanone (>99\%), 2,3,3-trimethylindolenine (98\%), iodoethane (99\%), 3- bromopropyne (80\% in toluene) were purchased from Aladdin Industrial Corporation (Shanghai, China). 1(tert butyloxycarbonyl) piperazine (>98\%) was purchased from J\&K Scientific Ltd. TLC was carried out on silica gel coating with aluminum sheets equipped with F254 indicator. Particle size of silica gel using for column separation was $0.063-0.200 \mathrm{~mm}$. All other chemicals and solvents were of analytic reagent grade. Milli-Q water with a resistivity of $18.2 \mathrm{M} \Omega \cdot \mathrm{cm}$ was used throughout all experiments.

\subsection{Instrumentations}

Nuclear magnetic resonance (NMR) spectrum were recorded on a Bruker AV250 NMR spectrometer in Fourier transform mode. High performance liquid chromatography (HPLC) analysis was carried out on an Agilent HPLC systems with a 1100 Series Quaternary pump, a 1200 Series Diode detector and a Merck Chromolich Performance RP18e 100-3 mm HPLC column. Methanol and acetonitrile was used as the mobile phase. UV-Vis absorption spectrum were recorded on a Lambda 900 spectrometer (Perkin Elmer). Fluorescence spectra were measured on a TIDAS II spectrometer (J\&M). The $\mathrm{pH}$ measurements were carried out on a Mettler-Toledo Delta $320 \mathrm{pH}$ meter.

\subsection{Synthesis}

\subsubsection{Synthesis of 1-(prop-2-yn-1-yl) piperazine (a2, Fig. 1)}

It was synthesized according to the reported literature [49]. Typically, 1-(tert butyloxycarbonyl) piperazine (3.7 g, $20 \mathrm{mmol}), 3$-bromopropyne $(1.9 \mathrm{~mL}, 22 \mathrm{mmol})$ and $\mathrm{K}_{2} \mathrm{CO}_{3}(4.1 \mathrm{~g}, 30 \mathrm{mmol})$ were dissolved in $\mathrm{CH}_{3} \mathrm{CN}(60$ $\mathrm{mL})$. After then the solution was stirred at $60^{\circ} \mathrm{C}$ for $8 \mathrm{~h}$. When cooling down to room temperature (R.T.), the solution was evaporated under reduced pressure. The obtained residue was re-dissovled in dichloromethane (DCM), followed by washing with water twice. The crude product was then purified through silica column chromatography to obtain tert-butyl 4-(prop-2-yn-1yl)piperazine-1-carboxylate (a1). a1 was then dissolved in DCM/TFA ( $\mathrm{v}: \mathrm{v}=1: 1)$ and the solution was stirred at R.T. for $2 \mathrm{~h}$. The solution was removed under a stream of compressed air. The residue was dissolved in ethyl acetate (EtOAc) and washed with $\mathrm{NaHCO}_{3}$ solution. a2 was afforded as a yellow, hygroscopic solid (actual yield $=0.98 \mathrm{~g}$; theoretical yield $=2.51 \mathrm{~g}$; yield $\%=39 \%$ ).

\subsubsection{Synthesis of 2-chloro-3-(hydroxymethylene)cyclohex-1- enecarbaldehyde (b1, Fig. 1)}

It was synthesized according to the reported literature [50]. Specifically, Fresh distilled dimethylformamide (DMF) $(10 \mathrm{~mL}, 135 \mathrm{mmol})$ was added into a $100 \mathrm{~mL}$ two-neck round flask under argon atmosphere. After that, DCM $(10 \mathrm{~mL})$ containing phosphorus oxychloride 


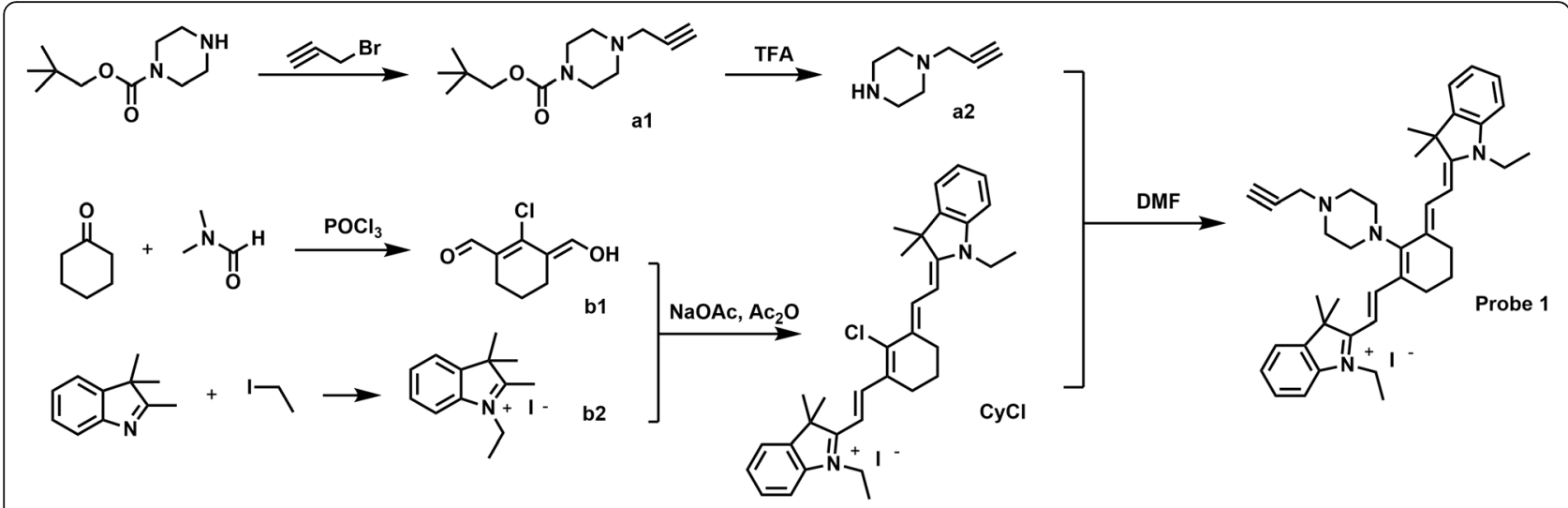

Fig. 1 Synthetic route for probe 1

(10 mL, $65 \mathrm{mmol}$ ) was added dropwise within $30 \mathrm{~min}$ at $0{ }^{\circ} \mathrm{C}$. The solution was stirred at R.T. for $30 \mathrm{~min}$, followed by slowly adding cyclohexanone $(2.5 \mathrm{~g}, 25$ $\mathrm{mmol}$ ) via a syringe. The resulting solution was reflux for $3 \mathrm{~h}$. When cooling down to R.T., the mixture was poured into cold water then stood in refrigerator overnight. b1 was filtered and washed with water, followed by drying in vacuum as yellow solid (actual yield $=3.10$ g; theoretical yield $=4.55 \mathrm{~g}$; yield $\%=68 \%$ ).

\subsubsection{Synthesis of 1-ethyl-2,3,3-trimethyl-3H-indol-1-ium iodide (b2, Fig. 1)}

It was synthesized according to the reported literature [50]. Typically, 2,3,3-trimethylindolenine $(3.18 \mathrm{~g}, 20$ $\mathrm{mmol})$ was dissolved in toluene $(5 \mathrm{~mL})$, iodoethane $(3.12 \mathrm{~g}, 20 \mathrm{mmol})$ was then added dropwise at R.T.. The solution was kept at $80^{\circ} \mathrm{C}$ for $12 \mathrm{~h}$, cooling down to room temperature and filtered. b2 was obtained as a pink solid (actual yield $=5.62 \mathrm{~g}$; theoretical yield $=6.30 \mathrm{~g}$; yield $\%=89 \%)$.

\subsubsection{Synthesis of 2-[2-[2-Chloro-3-[(1,3-dihydro-3,3- dimethyl-1-ethyl-2H-indol-2-ylidene)ethylidene-1-} cyclohexen-1-yl]ethenyl]-3,3-dimethyl-1-ethylindolium iodide (CyCl, Fig. 1)

It was synthesized according to the reported literature [50]. Typically, b2 $(1.83 \mathrm{~g}, 5.8 \mathrm{mmol})$, sodium acetate $(0.48 \mathrm{~g}, 18 \mathrm{mmol})$ and the intermediate compound b1 $(0.5 \mathrm{~g}, 2.9 \mathrm{mmol})$ were dissolved in $8 \mathrm{~mL}$ acetic anhydride under argon atmosphere. The mixture was stirred at $130^{\circ} \mathrm{C}$ for $3 \mathrm{~h}$. When cooling down to R.T., the mixture was poured into diethyl ether. The precipitate was washed through diethyl ether and aqueous potassium iodide solution. The crude product was then purified through column chromatography with $\mathrm{MeOH} / \mathrm{DCM}$ (v: $\mathrm{v}=1: 10$ ) as eluent to afford a metallic green solid (actual yield $=1.80 \mathrm{~g}$; theoretical yield $=1.97 \mathrm{~g}$; yield $\%=91 \%$ ).
2.3.5 Synthesis of 3H-indolium, 1-ethyl-2-[2-[3-[2-(1-ethyl1,3-dihydro-3,3-dimethyl-2H-indol-2-ylidene)ethylidene]-2-[1(prop-2-yn-1-yl)piperazinyl]-1-cyclohexen-1-yl]ethenyl]-3,3dimethyl-, iodide (probe 1, Fig. 1)

$\mathrm{CyCl}$ (319 mg, $0.5 \mathrm{mmol}$ ) and a2 (310 mg, $2.5 \mathrm{mmol}$ ) were dissolved in dry DMF $(10 \mathrm{~mL})$. The solution was stirred at R.T. overnight. The solution was then removed under high reduced pressure, and the crude product was purified through column chromatography with $\mathrm{MeOH} /$ DCM (v:v $=1: 20)$ as eluent to obtain a blue solid (actual yield $=276 \mathrm{mg}$; theoretical yield $=363 \mathrm{mg}$; yield $\%=76 \%$ ).

\subsection{Measurement method}

The fluorescence measurement were performed with excitation wavelength fixed at $510 \mathrm{~nm}$. A water/ethanol 9/ $1(\mathrm{v} / \mathrm{v})$ mixture solvent was used to ensure probe $\mathbf{1}$ were completely dissolved. A $0.5 \mathrm{mM}$ stock solution of probe 1 was prepared in above solution. A $1 \mathrm{mM}$ stock solution of $\mathrm{Ag}^{+}$was also prepared by dissolving $\mathrm{AgNO}_{3}$ in Milli-Q water. Then a serious of probe $\mathbf{1}$ and $\mathrm{Ag}^{+}$complex solution were prepared by adding each probe $\mathbf{1}$ stock solution to $100 \mathrm{~mL}$ volumetric flasks containing $\mathrm{Ag}^{+}$stock solution and diluted with HEPES buffer. The obtained solution was water/ethanol $=$ 90:1 (v/v).

\section{Result and discussion}

3.1 Construction and characterization of intermediate and probe 1

In order to obtain a specific fluorescent probe for Ag ion detection, an alkynyl piperazine unit as Ag ion capture was first synthesized. As shown in Fig. 1, 1-boc-piperazine as starting material was conjugated with 3-bromopropyne via substitution reaction, and subsequently deprotect the boc group using trifluoroacetic acid. The Ag recognition unit a2 could be post-synthetically to further functionalize to the signal fluorophore. The chemical structure of a2 was confirmed by ${ }^{1} \mathrm{H}$ NMR (Figure S1, Supporting information). 
To synthesize probe $\mathbf{1}$, first, the fluorophore $\mathrm{CyCl}$ was synthesized via the condensation of the synthesized aromatic quaternary ammonium salt b2 with the condensing agent b1. Then the obtained fluorophore was decorated with the $\mathrm{Ag}$ ion capture to get a blue solid probe $\mathbf{1}$. All the intermediate and probe 1 were obtained in a high yield and fully characterized by ${ }^{1} \mathrm{H}$ NMR (Figures S2, S3, S4 and S5, Supporting information). Furthermore, to better understand the purity of the final probe 1, HPLC analysis was also performed (Figure S6, Supporting information). The main peak appeared in $\mathbf{1 2 . 8 7}$ min showed the peak of probe $\mathbf{1}$ with the integration of $94.5 \%$, which guarantee the high purity of probe $\mathbf{1}$ for further investigation.

\subsection{Fluorescence and UV-Vis spectral response of probe 1 to $\mathrm{Ag}^{+}$}

The fluorescence response of probe $\mathbf{1}$ was then studied by fluorescence spectrometer. Figure 2 shows probe 1 $(1.0 \mu \mathrm{M})$ displayed a strong emission of $\mathrm{Cy} 7$ fluorophore with $510 \mathrm{~nm}$ excitation and emission wavelength ranging from $540 \mathrm{~nm}$ to $860 \mathrm{~nm}$ in HEPES buffer (water/etha$\mathrm{nol}=90: 1, \mathrm{v} / \mathrm{v})$. However, upon gradual addition of $\mathrm{Ag}^{+}$ solution, the $781 \mathrm{~nm}$ emission maxima decreased dramatically. When the $\mathrm{Ag}^{+}$concentration reach up to $1.0 \mu \mathrm{M}$, the maximum fluorescent intensity was quenched till $80 \%$ and subsequently extend the limit to 95\% decreasing at $4.0 \mu \mathrm{M} \quad \mathrm{Ag}^{+}$concentration.
Meanwhile, the insert figure shows there is also a new peak appeared at $558 \mathrm{~nm}$. The linear relationship between the fluorescent intensity at $781 \mathrm{~nm}$ and the additional $\mathrm{Ag}^{+}$concentration was calculated (Figure S7, Supporting information). The plotted curve has an extremely low Adj. R-Square with the value of 0.512, which mean the data points cannot fit well with the linear line. As a contrast, Fig. 3 shows the ratio of emission intensity, $\mathrm{I}_{558} / \mathrm{I}_{781}$, gradually increased upon $\mathrm{Ag}^{+}$addition, fitting well with the plotted curve with the intercept $(\sigma)$ of 0.005 and slope (S) of 0.702 as well as the Adj. R-Square value of 0.992 , which could be further used for determining the concentration of $\mathrm{Ag}^{+}$. The linear range of probe 1 for detection $\mathrm{Ag}^{+}$was found to be $5.0 \times 10^{-8} \mathrm{M}$ to $4.0 \times 10^{-6} \mathrm{M}$, which is comparable with other methods based on chemosensor for metal ion detection [51]. Moreover, the limit of detection (LOD) was calculated according to the formula: $\mathrm{LOD}=3.3 \sigma / \mathrm{S}$. The limit of quantification was expressed according to the formula: $\mathrm{LOQ}=10 \sigma / \mathrm{S}$. Therefore, the LOD was calculated to be $2.3 \times 10^{-8} \mathrm{M}$ and LOQ to be $7.1 \times 10^{-8} \mathrm{M}$.

$\mathrm{UV}$-Vis spectrum of probe $\mathbf{1}$ was also carried out for better understanding the variation of fluorescence spectrum. Figure 4 shows free probe $\mathbf{1}$ exhibits the only absorption peak at $670 \mathrm{~nm}$. When gradually adding $\mathrm{Ag}^{+}$ into the solution, the peak intensity at $670 \mathrm{~nm}$ decreases, while a new peak at $310 \mathrm{~nm}$ arises. The obvious blueshift is accordance with the observed color change of

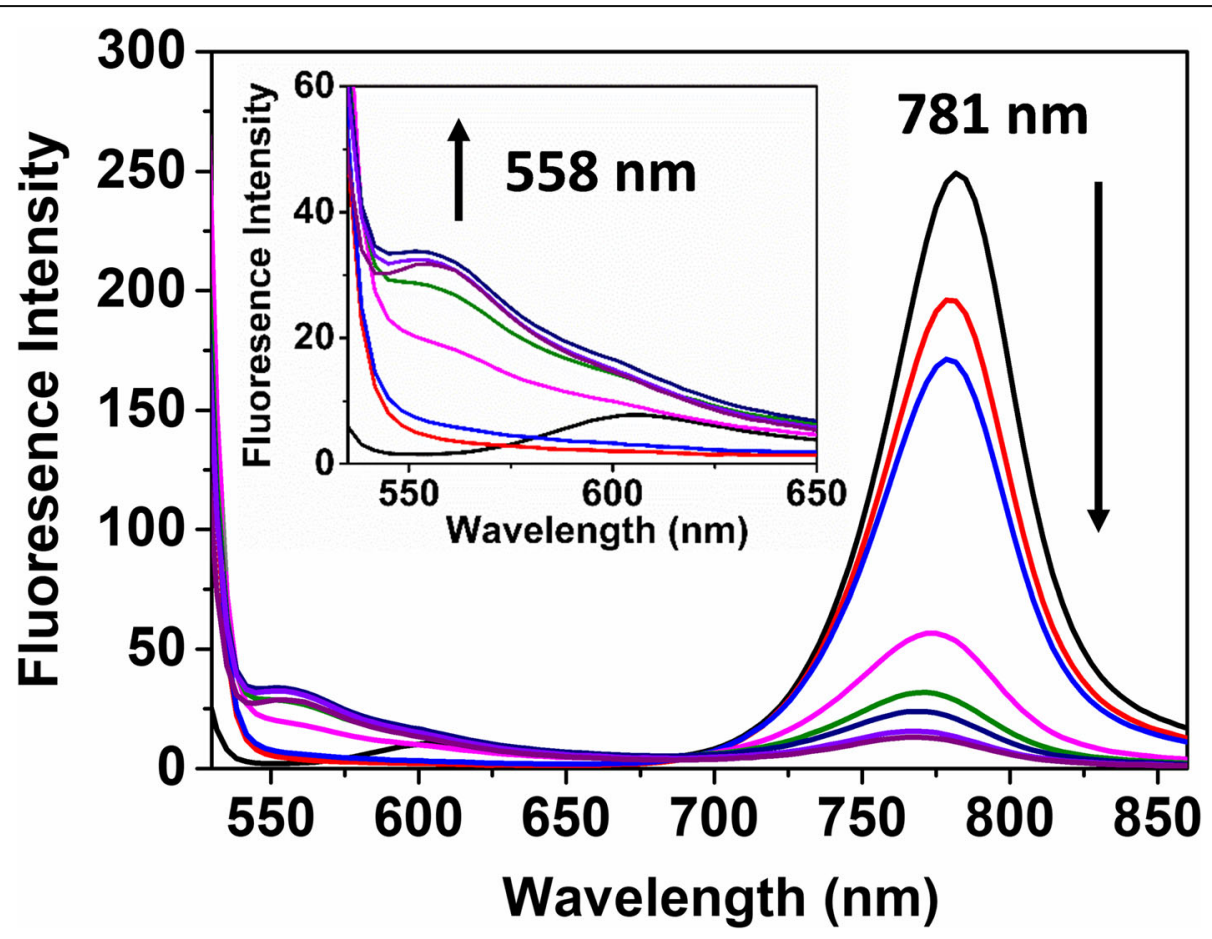

Fig. 2 Fluorescence spectrum of probe $\mathbf{1}(1.0 \mu \mathrm{M})$ upon adding of $\mathrm{Ag}^{+}(0,0.05,0.1,0.5,1.0,2.0,3.0,4.0 \mu \mathrm{M})$ in HEPES buffer solution (pH 8.0). The insert figure shows the enlarged spectrum between $540 \mathrm{~nm}$ and $650 \mathrm{~nm}$ 


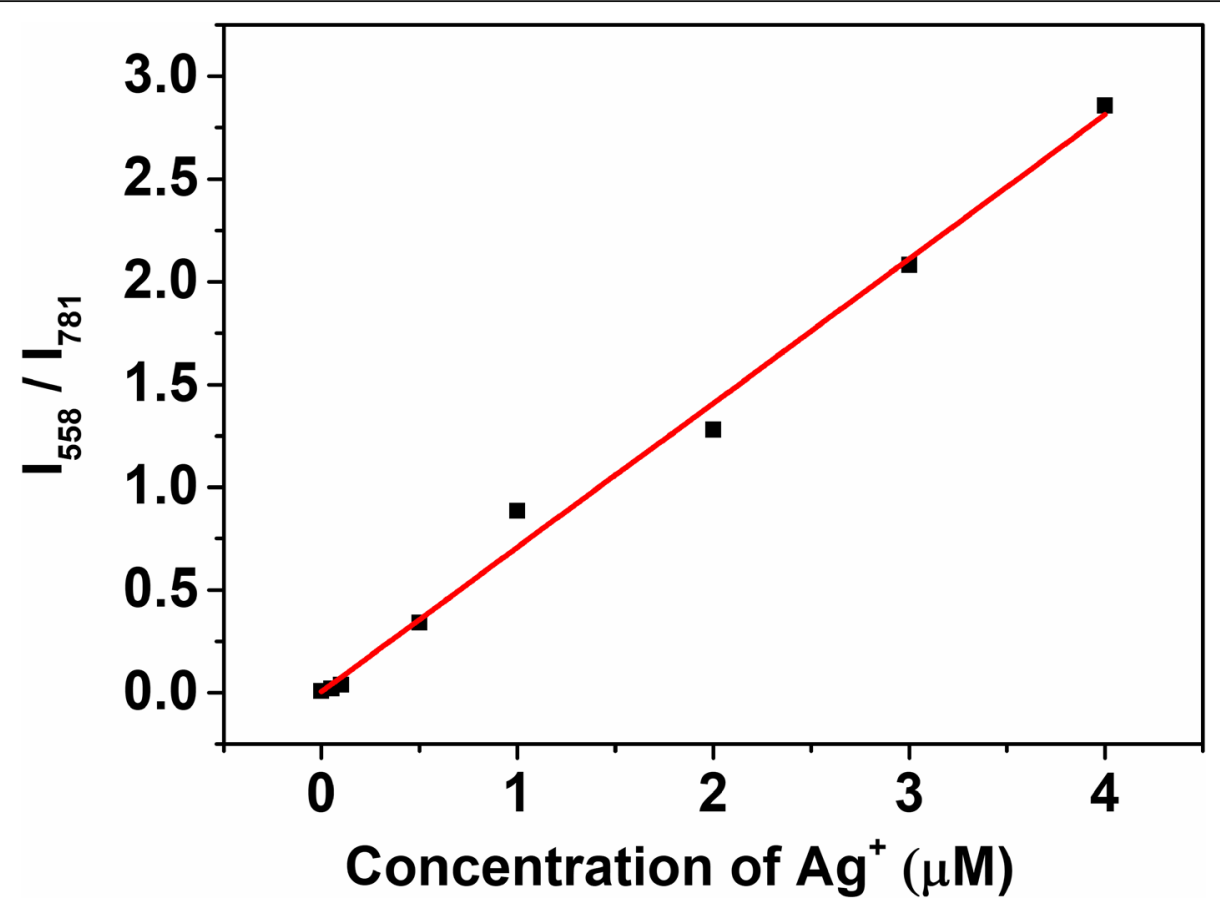

Fig. 3 The curve is plotted with the fluorescence intensity ratio $\left(I_{558} / l_{781}\right)$ versus $\mathrm{Ag}^{+}$concentration

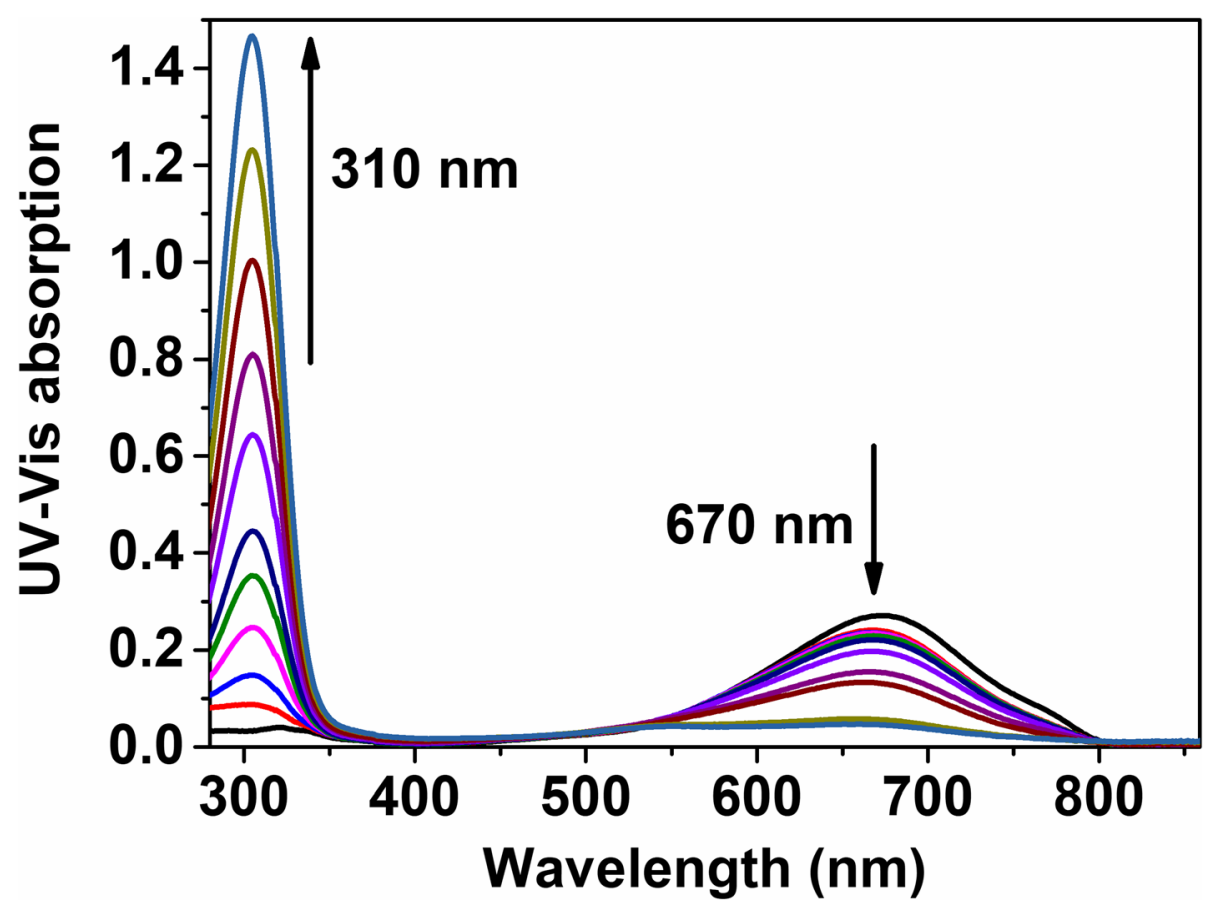

Fig. 4 UV-Vis spectrum of probe $\mathbf{1}$ upon adding of $\mathrm{Ag}^{+}(0,0.05,0.1,0.5,1.0,2.0,3.0,4.0,5.0,6.0,7.0 \mu \mathrm{M})$ in HEPES buffer solution (pH 8.0) 


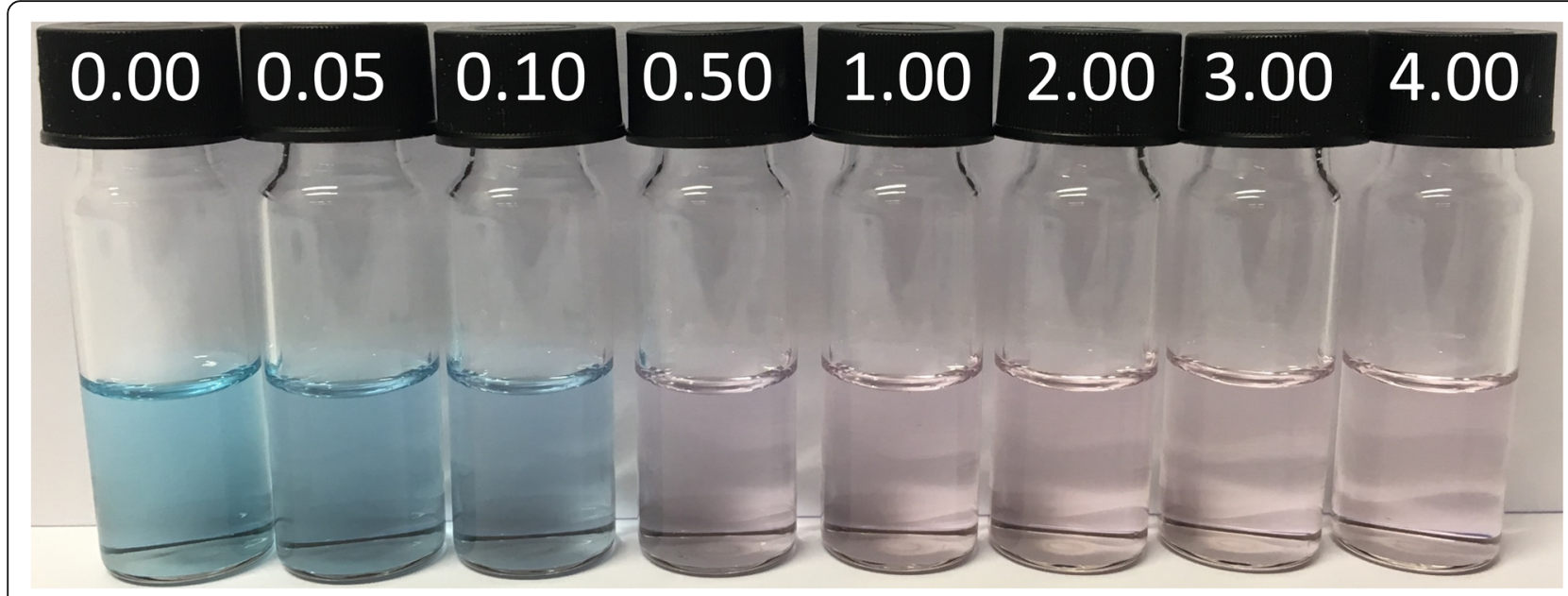

Fig. 5 Color changes observed upon addition of different concentration ( $\mu \mathrm{M})$ of $\mathrm{Ag}^{+}$to the solution of probe $\mathbf{1}$ in HEPES buffer solution ( $\mathrm{pH}$ 8.0)

solution varying from blue to light red, which allows the "naked-eye" detection of $\mathrm{Ag}^{+}$shown in Fig. 5.

3.3 The selectivity to various metal ion as well as common anion and $\mathrm{pH}$ effect of probe 1

In order to explore whether other metal ion or common anions make a potential interference to probe 1, fluorescence titration experiments were carried out to evaluate other 12 types of metal ion and common anions which are usually found in wastewater samples under the same conditions. As shown in Fig. 6, no observation of fluorescent spectral changes for $1 \mu \mathrm{M}$ probe 1 when treating with most of these ions $(0.5 \mu \mathrm{M})$ at $\mathrm{pH}$. Only adding $\mathrm{Cr}^{3+}$ caused a slight decreasing of fluorescent intensity of probe $\mathbf{1}$. However, the overwhelming decreasing fluorescent intensity at $781 \mathrm{~nm}$ upon addition of $\mathrm{Ag}^{+}$ indicates a highly selectivity for $\mathrm{Ag}^{+}$over other tested metal ion. $\mathrm{Mg}^{2+}, \mathrm{Al}^{3+}, \mathrm{NO}_{3}{ }^{-}$and $\mathrm{SO}^{4-}$ were further chosen to investigate whether concentrations may affect the anti-interference experiment. As shown in Fig. 7, upon addition of these ions with different concentration $(0.5 \mu \mathrm{M}, 1 \mu \mathrm{M}$ and $2 \mu \mathrm{M})$, the fluorescent ratio showed

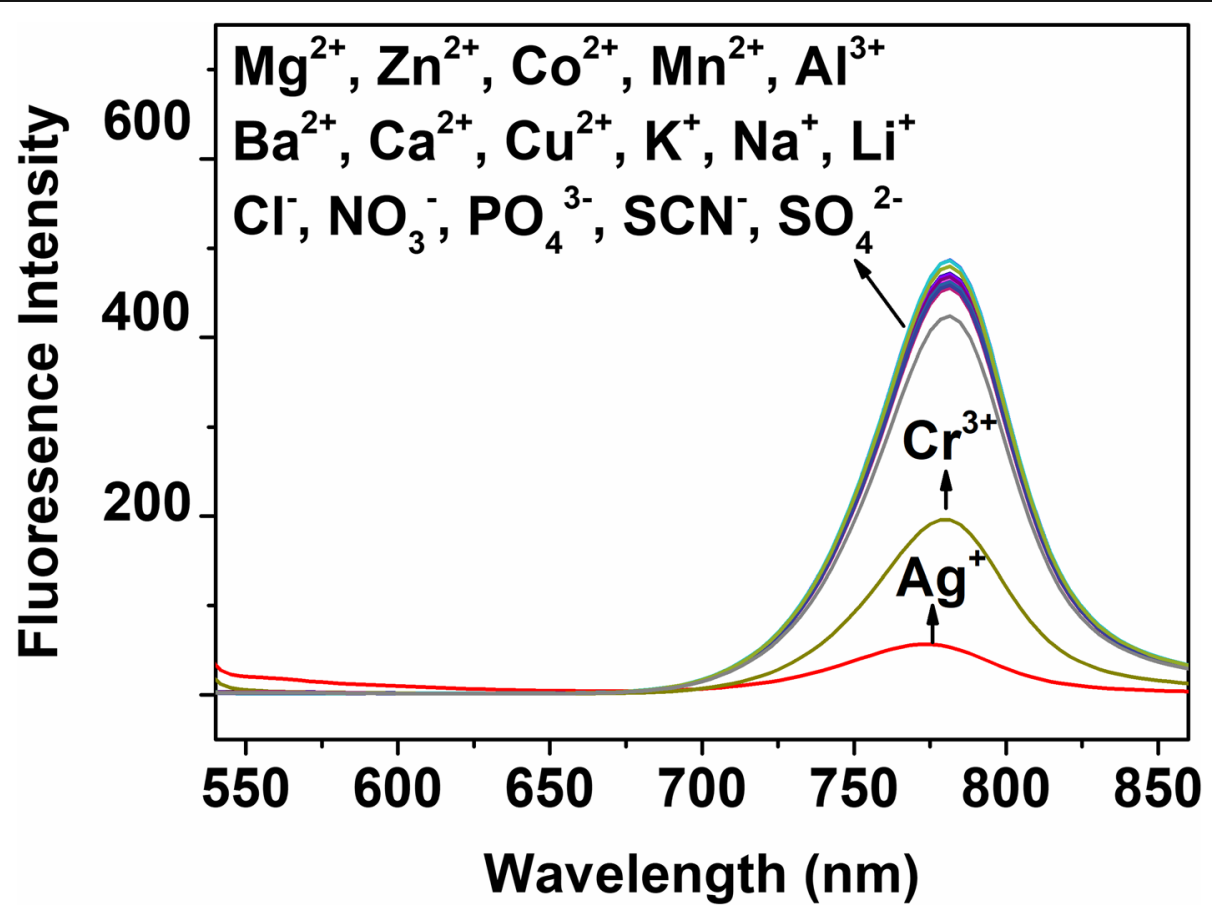

Fig. 6 Fluorescence intensity of probe $\mathbf{1}$ in HEPES buffer solution with various metal ions and anions 


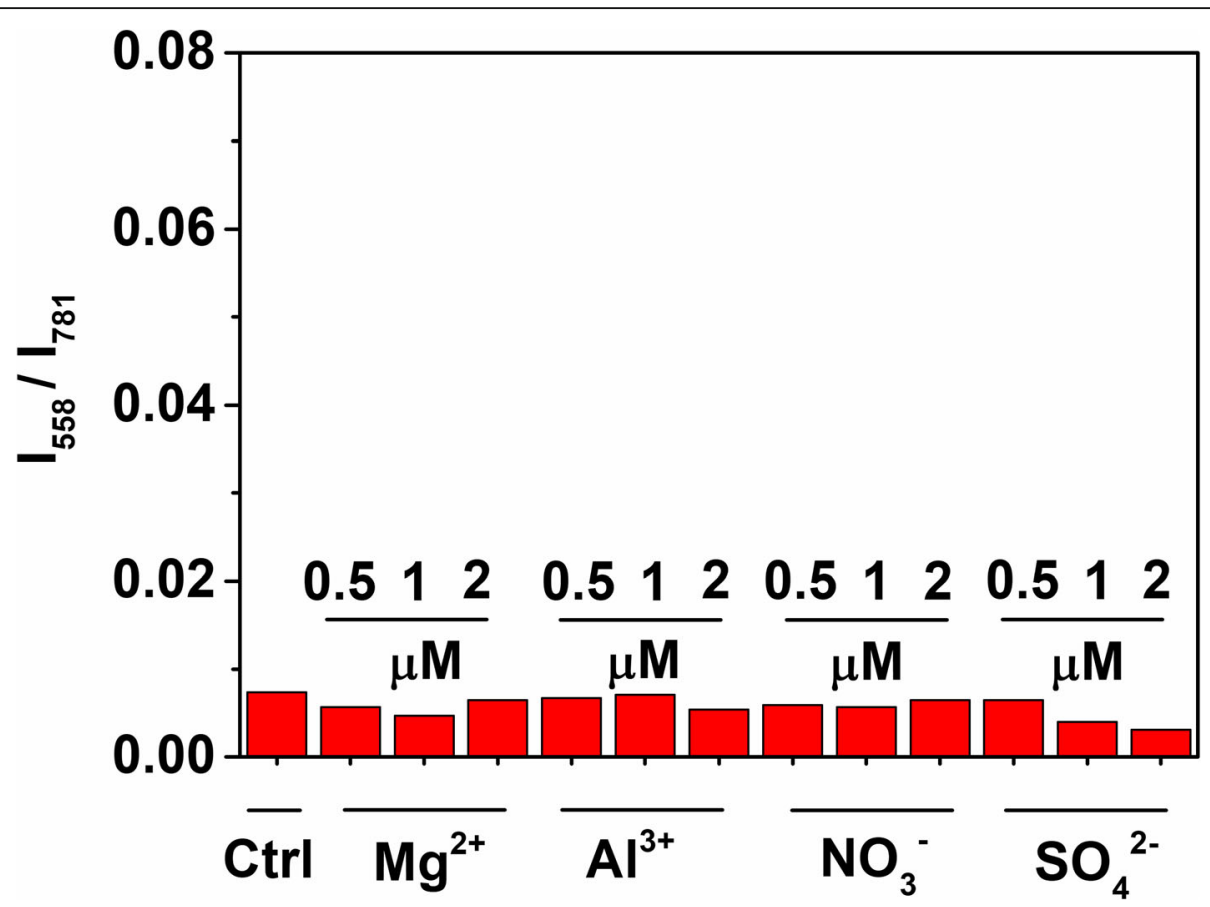

Fig. 7 Fluorescence intensity ratio $\left(l_{558} / l_{781}\right)$ of probe $\mathbf{1}$ in HEPES buffer solution with different concentrations of ions and anions

almost no change even when the concentration of each ion reached $2 \mu \mathrm{M}$. All these results confirmed that probe 1 could be used as a selective chemosensor for detecting $\mathrm{Ag}^{+}$in the presence of other common competing ions which can be found in wastewater wastewater.
The performance of the fluorescent probe usually depends on the $\mathrm{pH}$ value in real wastewater and causes a significant effect on the testing metal ion. This is owing to the protonation of probe dye in the acidic environment or the hydrolysis of metal ion in the basic environment. Therefore, whether $\mathrm{pH}$ influence the fluorescence

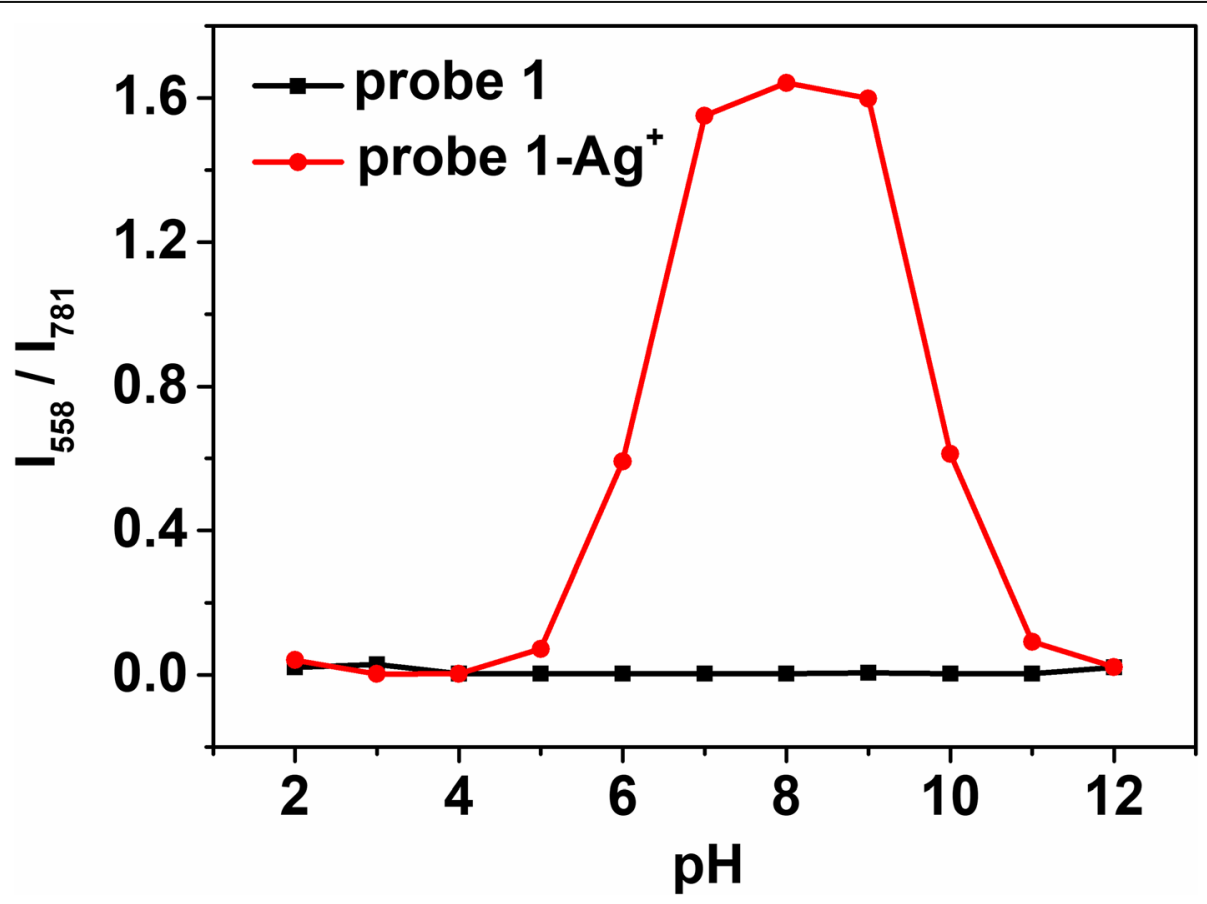

Fig. 8 Effect of $\mathrm{pH}$ on the fluorescence intensity ratio $\left(\mathrm{I}_{558} / \mathrm{I}_{781}\right)$ of probe $\mathbf{1}$ (black line) and $\mathbf{1}+\mathrm{Ag}^{+}$(red line) 


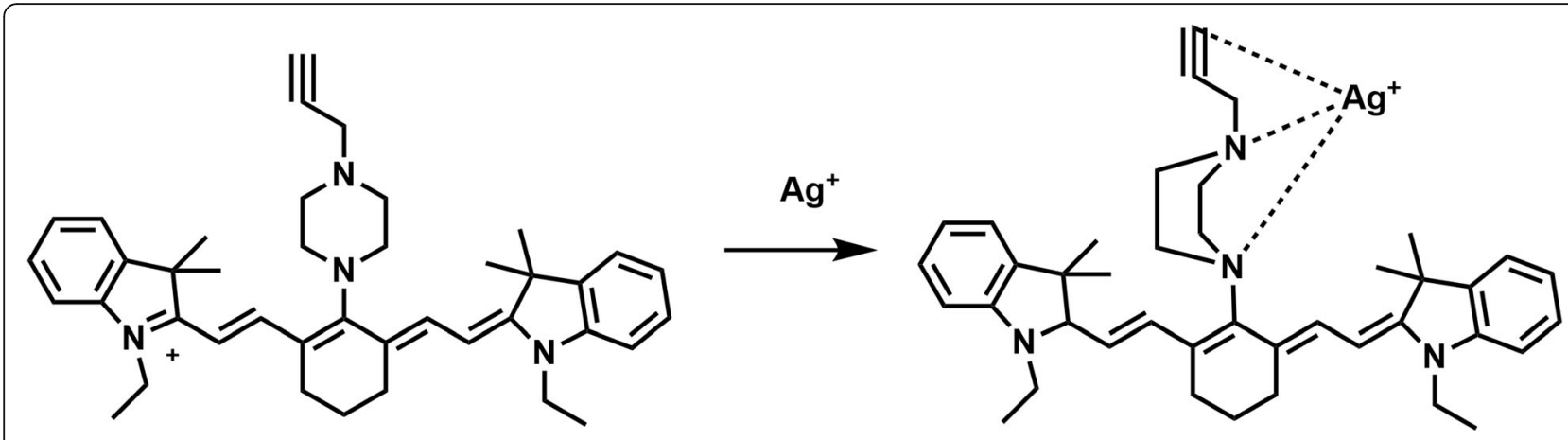

Fig. 9 Proposed binding mechanism of probe $\mathbf{1}$ in the presence of $\mathrm{Ag}^{+}$

intensity ratio $\left(\mathrm{I}_{558} / \mathrm{I}_{781}\right)$ of probe $\mathbf{1}$ in the presence of $\mathrm{Ag}^{+}$was further studied. These experiments were executed at a varying $\mathrm{pH}$ from 2.0 to 12.0 , with fixing probe 1 concentration of $1.0 \mu \mathrm{M}$ and $\mathrm{Ag}^{+}$of $2.0 \mu \mathrm{M}$. Figure 8 shows the intensity ratio of free probe $\mathbf{1}$ has no remarkable change at different $\mathrm{pH}$. However, when $\mathrm{pH}$ ranging from 5.0 to 11.0, the fluorescent intensity ratio of $1-\mathrm{Ag}^{+}$ complex strongly depend on the $\mathrm{pH}$ value. The response behavior of complex exhibits largest $\mathrm{I}_{558} / \mathrm{I}_{781}$ ratio at $\mathrm{pH}$ 8 , while dramatically decreases below $\mathrm{pH}=5.0$ or above $\mathrm{pH}=11.0$ region. This is because protonation may hinder probe $\mathbf{1}$ binding to $\mathrm{Ag}^{+}$when in strong acidic condition. While in strong basic condition, the Ag ion may form $\mathrm{AgOH}$ precipitation which reduce the real $\mathrm{Ag}$ concentration, therefore cause the decreasing of fluorescent intensity at $558 \mathrm{~nm}$ and further reducing the $\mathrm{I}_{558} / \mathrm{I}_{781}$ ratio. Thus, the neutral pH ranging from 6.0 to 8.0 could be chosen for further investigation and applications.

\subsection{Investigation of binding mechanism}

It is meaningful to modulate the $\pi$-electron system of Cy7 fluorophore and to propose new method to develop Cy7-based fluorescent probe [41]. Based on the 1:1 stoichiometric ratio of probe $\mathbf{1}$ and $\mathrm{Ag}^{+}$obtained by fluorescence spectrum, a coordination mechanism between $\mathrm{Ag}$ ion and probe $\mathbf{1}$ was established in Fig. 9. In this model, the two nitrogen atoms in the piperazine unit and the terminal alkynyl group coordinate with the silver ion, which promotes the large hypsochromic shifts in both $\mathrm{UV}-\mathrm{Vis}$ spectra and fluorescent spectra of probe $\mathbf{1}$. Via the disruption of the $\pi$-electron system caused by $\mathrm{Ag}^{+}$, the tunable absorption/fluorescence performances could be shorten by destruction of the pull-push $\pi$-conjugation system of Cy7 structure. The mechanism is also similar to other cyanine-based chemosensors reported by Zhu and coworkers [47]. They also proposed and synthesized a ratiometric probe for Ag ion detection. Compared with their work, the Ag capture unit of our work contains one more alkynyl unit, which has superior alkynophilicity because of the $\pi$-coordination between the $\mathrm{Ag}$ ion and alkynyl group. The $\mathrm{d}^{10}$ of electronic configuration of $\mathrm{Ag}$ ion contributes to the activation of alkyne, favoring interactions with the $\pi$-bond of alkynes, leading to the formation of a silver- $\pi$ complex [52]. This makes probe 1 a higher sensitive and selective to $\mathrm{Ag}$ ion. Further insight of the binding mechanism was proved by ${ }^{1} \mathrm{H}$ NMR (Figure S8, Supporting information). The $\mathrm{H}$ proton signals of piperazine unit and alkynyl group in free probe 1 were located at $\delta 3.73,3.79$ and $2.85 \mathrm{ppm}$, respectively. However, upon adding of $\mathrm{Ag}^{+}$(1.0 equiv.), these three signal shift to lower $\delta$ value (3.77 and 3.85 for piperazine proton, and 2.99 for terminal alkynyl group). These result strongly demonstrated the complexation reaction of probe $\mathbf{1}$ with $\mathrm{Ag}^{+}$occurred at nitrogen

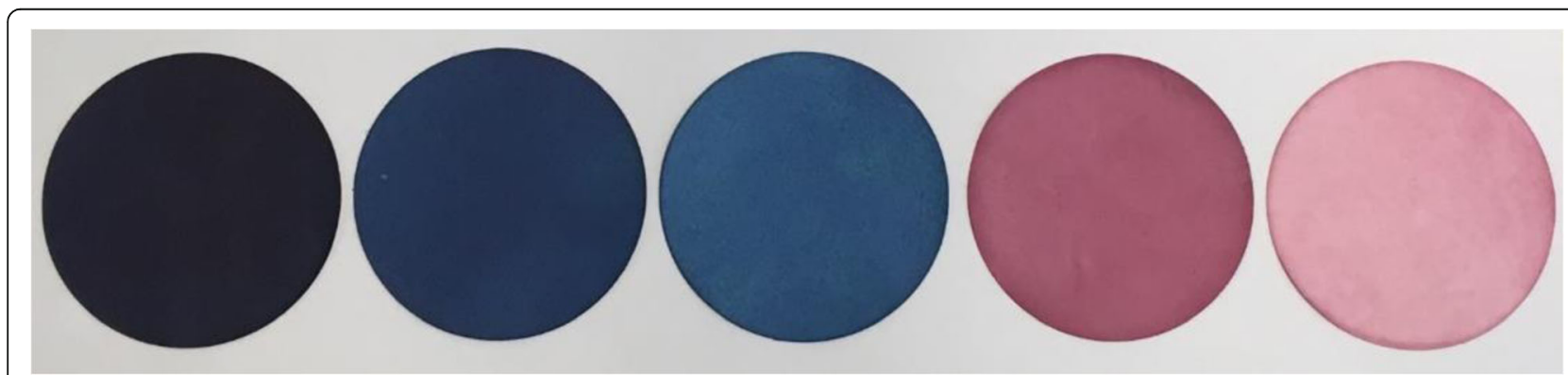

Fig. 10 Photographs showing the color changes of probe $\mathbf{1}$ upon immersing in different concentration of $\mathrm{Ag}^{+}$in HEPES solution (from left to right: $0.00,0.05,0.10,0.50,1.00 \mu \mathrm{M}$ ) 
Table 1 Determination of $\mathrm{Ag}^{+}$from real wastewater samples

\begin{tabular}{llll}
\hline Sample & AAS $(\mu \mathrm{M})$ & Probe $1(\mu \mathrm{M})$ & Relative error $(\%)$ \\
\hline Wastewater $1^{\mathrm{a}}$ & 0.96 & 1.00 & 4.16 \\
${\text { Wastewater } 2^{\mathrm{a}}}$ & 0.52 & 0.50 & -3.84 \\
${\text { Wastewater } 3^{\mathrm{b}}}$ & 0.49 & 0.50 & -2.04
\end{tabular}

${ }^{a}$ The wastewater samples from photography company

${ }^{\mathrm{b}}$ The wastewater sample from leather research laboratory

and alkynyl position, and thereby leading to the obvious absorption/fluorescence change.

\subsection{Preliminary application for preparing test strips and applicability for real wastewater samples}

Analytic test strips for metal ion provide easy and convenient ways for real-time analysis and indicating ion in industrial wastewater without costly instruments [53, 54]. Noting that the obvious color change when adding $\mathrm{Ag}^{+}$, the test strips were obtained when the filter paper immersed into a saturated probe $\mathbf{1}$ ethanol solution, followed by shaking for $4 \mathrm{~h}$. Then, these strips dried in air and subsequently treated with $\mathrm{Ag}^{+}$solution ranging from $0 \mu \mathrm{M}$ to $4 \mu \mathrm{M}$ in HEPES buffer solution. Figure 10 shows the colors were clearly turned from dark blue to light red, demonstrating the $\mathrm{Ag}^{+}$were simply and successfully detected by the test strips, and realizing the cost-effective strategy for naked-eye detection of $\mathrm{Ag}^{+}$.

In order to estimate the potential application for these test strips, real wastewater samples and from a photography company and a leather research laboratory were also collected for $\mathrm{Ag}^{+}$detection. The wastewater sample from leather research laboratory was diluted to meet the linear range of the test strips. These test strips exhibit comparable responses to $\mathrm{Ag}$ ion. Table 1 summarized the values from the chemosensor were comparable to those calculated by the AAS method with a relative error of less than $5 \%$, which demonstrating these as-fabricated could be potentially applied in real wastewater samples.

\section{Conclusion}

In summary, a colorimetric chemosensor probe $\mathbf{1}$ based on tricarbocyanine derivative for $\mathrm{Ag}^{+}$detection was successfully developed. Upon adding $\mathrm{Ag}^{+}$to probe 1 solution, the fluorescent spectrum and UV-Vis spectrum show hypsochromic shifts which reflect silver-induced destruction of the $\pi$-electron system in $\mathrm{Cy} 7$ structure. The obvious absorption and emission shifts make naked-eye detection possible. Probe $\mathbf{1}$ also exhibits high sensitive performance and excellent selectivity toward $\mathrm{Ag}^{+}$over other normally used metal ions in neutral $\mathrm{pH}$. As a proof-of-concept application, a test strip for Ag ion detection was developed in this work. The fabricated test strip can be used to trace amounts of hazardous $\mathrm{Ag}^{+}$in real industrial wastewater, with a good accuracy and precision for the analysis of $\mathrm{Ag}^{+}$.

\section{Supplementary information}

Supplementary information accompanies this paper at https://doi.org/10. 1186/s42825-020-00031-2.

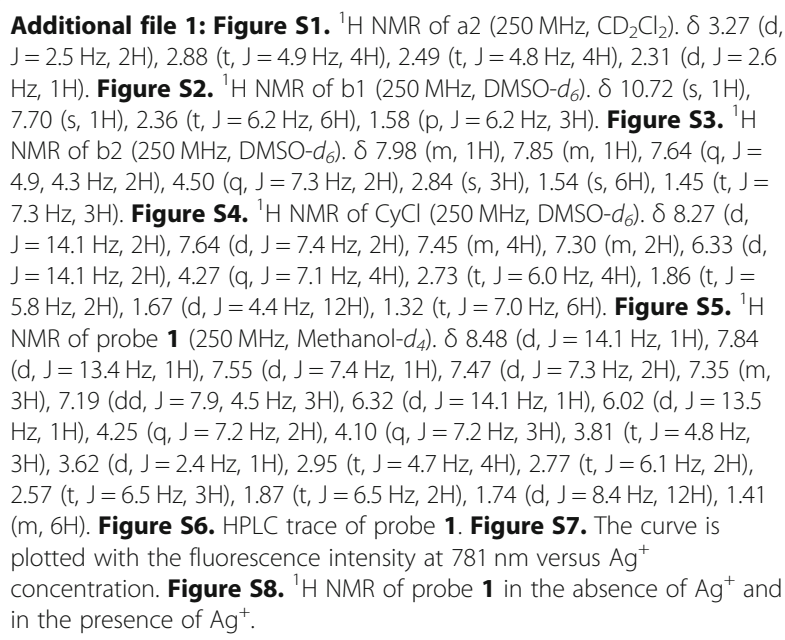

\section{Abbreviations}

MOFs: Metal-organic frameworks; QDs: Quantum dots; ICP-AES: Inductively coupled plasma atomic emission spectrometry; ICP-MS: Inductively coupled plasma mass spectrometry; AAS: Atomic absorption spectrometry;

Cy7: Heptamethine cyanine; DCM: Dichloromethane; TFA: Trifluoroacetic acid; EtOAc: Ethyl acetate; DMF: Dimethylformamide; TLC: Thin layer

chromatography; R.T.: Room temperature

\section{Acknowledgements}

We thank National Natural Science Foundation of China (21808028), Science and Technology Foundation of Liaoning Province (2019-BS-047), and the Fundamental Research Funds for the Central Universities (2018011013) for financial support.

\section{Authors' contributions}

$X L$ performed the experiments. $X L$ and $X Z$ wrote this manuscript. $X Z$ and $W S$ proposed the scientific idea, the methods used in this study. All authors read and approved the final manuscript.

\section{Funding}

This work was financially supported by National Natural Science Foundation of China (21808028), Science and Technology Foundation of Liaoning Province (2019-BS-047), and the Fundamental Research Funds for the Central Universities (2018011013).

\section{Availability of data and materials}

${ }^{1} \mathrm{H}$ NMR spectra of all compounds used in this manuscript are listed in the supporting information.

\section{Competing interests}

The authors declare that they have no competing interests.

\section{Author details}

${ }^{1}$ State Key Laboratory of Fine Chemicals, Dalian University of Technology, 2 Linggong Road, Hi-Tech Zone, Dalian 116024, China. ${ }^{2}$ Max Planck Institute for Polymer Research, Ackermannweg 10, 55128 Mainz, Germany.

Received: 11 March 2020 Accepted: 25 June 2020

Published online: 03 August 2020

\section{References}

1. Barriada JL, Tappin AD, Evans EH, Achterberg EP. Dissolved silver measurements in seawater. TrAC Trends Anal Chem. 2007;26(8):809-17.

2. Ratte HT. Bioaccumulation and toxicity of silver compounds: a review. Environ Toxicol Chem. 1999;18(1):89-108. 
3. Croteau M-N, Misra SK, Luoma SN, Valsami-Jones E. Silver bioaccumulation dynamics in a freshwater invertebrate after aqueous and dietary exposures to nanosized and ionic Ag. Environ Sci Technol. 2011;45(15):6600-7.

4. Liu G, Li K, Luo Q, Wang H, Zhang Z. PEGylated chitosan protected silver nanoparticles as water-borne coating for leather with antibacterial property. J Colloid Interface Sci. 2017:490:642-51.

5. Velmurugan P, Shim J, Kim H, Lim J-M, Kim SA, Seo Y-S, Kim J-W, Kim K, Oh B-T. Bio-functionalization of cotton, silk, and leather using different insitu silver nanoparticle synthesis modules, and their antibacterial properties. Res Chem Intermed. 2020;46:999-1015.

6. Greulich C, Braun D, Peetsch A, Diendorf J, Siebers B, Epple M, Köller M. The toxic effect of silver ions and silver nanoparticles towards bacteria and human cells occurs in the same concentration range. RSC Adv. 2012;2(17):6981-7.

7. Reidy B, Haase A, Luch A, Dawson KA, Lynch I. Mechanisms of silver nanoparticle release, transformation and toxicity: a critical review of current knowledge and recommendations for future studies and applications. Materials. 2013;6(6):2295-350.

8. Bundschuh M, Filser J, Lüderwald S, McKee MS, Metreveli G, Schaumann GE, Schulz R, Wagner S. Nanoparticles in the environment: where do we come from, where do we go to? Environ Sci Eur. 2018;30(1):1-17.

9. Schäfer B, Vom Brocke J, Epp A, Götz M, Herzberg F, Kneuer C, Sommer Y, Tentschert J, Noll M, Günther I. State of the art in human risk assessment of silver compounds in consumer products: a conference report on silver and nanosilver held at the BfR in 2012. Arch Toxicol. 2013;87(12):2249-62.

10. Korani M, Ghazizadeh E, Korani S, Hami Z, Mohammadi-Bardbori A. Effects of silver nanoparticles on human health. Eur J Nanomed. 2015;7(1):51-62.

11. Kazi TG, Afridi HI, Shah F, Arain SS, Brahman KD, Ali J, Arain MS. Simultaneous determination of silver and other heavy metals in aquatic environment receiving wastewater from industrial area, applying an enrichment method. Arab J Chem. 2016;9(1):105-13.

12. Nezhad HM, Karimi M, Shahheydari F. A sensitive colorimetric detection of ascorbic acid in pharmaceutical products based on formation of anisotropic silver nanoparticles. Trans F Nanotechnol. 2010;17(2):148-53.

13. Resano M, Aramendía M, Garcia-Ruiz E, Crespo C, Belarra MA. Solid sampling-graphite furnace atomic absorption spectrometry for the direct determination of silver at trace and ultratrace levels. Anal Chim Acta. 2006; 571(1):142-9.

14. Javanbakht M, Divsar F, Badiei A, Fatollahi F, Khaniani Y, Ganjali MR, Norouzi P, Chaloosi M, Ziarani GM. Determination of picomolar silver concentrations by differential pulse anodic stripping voltammetry at a carbon paste electrode modified with phenylthiourea-functionalized high ordered nanoporous silica gel. Electrochim Acta. 2009:54(23):5381-6.

15. Zejli H, de Cisneros JH-H, Naranjo-Rodriguez I, Temsamani K. Stripping voltammetry of silver ions at polythiophene-modified platinum electrodes. Talanta. 2007;71(4):1594-8.

16. Wilschefski SC, Baxter MR. Inductively coupled plasma mass spectrometry: introduction to analytical aspects. Clin Biochem Rev. 2019;40(3):115.

17. Krachler M, Mohl C, Emons H, Shotyk W. Analytical procedures for the determination of selected trace elements in peat and plant samples by inductively coupled plasma mass spectrometry. Spectrochim Acta B At Spectrosc. 2002;57(8):1277-89.

18. Chakrapani G, Mahanta P, Murty D, Gomathy B. Preconcentration of traces of gold, silver and palladium on activated carbon and its determination in geological samples by flame AAS after wet ashing. Talanta. 2001;53(6):1139-47.

19. Punithakumari G, Wu SP, Velmathi S. Highly selective detection of $\mathrm{Cr}^{3+}$ ion with colorimetric \& fluorescent response via chemodosimetric approach in aqueous medium. J Fluoresc. 2018;28(2):663-70.

20. Zhao J, Wang Y-N, Dong W-W, Wu Y-P, Li D-S, Zhang Q-C. A robust luminescent Tb (III)-MOF with Lewis basic pyridyl sites for the highly sensitive detection of metal ions and small molecules. Inorg Chem. 2016; 55(7):3265-71

21. Wang B, Yang Q, Guo C, Sun Y, Xie L-H, Li J-R. Stable Zr (IV)-based metalorganic frameworks with predesigned functionalized ligands for highly selective detection of Fe (III) ions in water. ACS Appl Mater Interfaces. 2017; 9(11):10286-95.

22. Wang F, Gu Z, Lei W, Wang W, Xia X, Hao Q. Graphene quantum dots as a fluorescent sensing platform for highly efficient detection of copper (II) ions. Sens Actuators B Chem. 2014;190:516-22.

23. Dong Y, Wang R, Li G, Chen C, Chi Y, Chen G. Polyamine-functionalized carbon quantum dots as fluorescent probes for selective and sensitive detection of copper ions. Anal Chem. 2012;84(14):6220-4.
24. Vikrant K, Kumar V, Kim K-H, Kukkar D. Metal-organic frameworks (MOFs): potential and challenges for capture and abatement of ammonia. J Mater Chem. 2017;5(44):22877-96.

25. Wang M, Leung K-H, Lin S, Chan DS-H, Kwong DW, Leung C-H, Ma D-L. A colorimetric chemosensor for $\mathrm{Cu}^{2+}$ ion detection based on an iridium (III) complex. Sci Rep. 2014;4(1):1-7.

26. Li Q, Guo Y, Shao S. A BODIPY based fluorescent chemosensor for $\mathrm{Cu}$ (II) ions and homocysteine/cysteine. Sensors Actuators B Chem. 2012;171:872-7.

27. Weng $Y-Q$, Teng Y-L, Yue F, Zhong Y-R, Ye B-H. A new selective fluorescent chemosensor for CU (II) ion based on zinc porphyrin-dipyridylamino. Inorg Chem Commun. 2007:10(4):443-6.

28. Zhang L-K, Tong Q-X, Shi L-J. A highly selective ratiometric fluorescent chemosensor for $\mathrm{Cd}^{2+}$ ions. Dalton Trans. 2013;42(24):8567-70.

29. Wang $Y$, Hu $X$, Wang $L$, Shang $Z$, Chao J, Jin W. A new acridine derivative as a highly selective 'off-on'fluorescence chemosensor for $\mathrm{Cd}^{2+}$ in aqueous media. Sensors Actuators B Chem. 2011;156(1):126-31.

30. Ellairaja S, Manikandan R, Vijayan MT, Rajagopal S, Vasantha VS. A simple highly sensitive and selective TURN-ON fluorescent chemosensor for the detection of cadmium ions in physiological conditions. RSC Adv. 2015;5(78):63287-95.

31. Kuwar A, Patil R, Singh A, Sahoo SK, Marek J, Singh N. A two-in-one dual channel chemosensor for $\mathrm{Fe}^{3+}$ and $\mathrm{Cu}^{2+}$ with nanomolar detection mimicking the IMPLICATION logic gate. J Mater Chem C. 2015;3(2):453-60.

32. Liu S-R, Wu S-P. New water-soluble highly selective fluorescent chemosensor for Fe (III) ions and its application to living cell imaging. Sensors Actuators B Chem. 2012;171:1110-6.

33. Zhou Y, Zhang J, Zhang L, Zhang Q, Ma T, Niu J. A rhodamine-based fluorescent enhancement chemosensor for the detection of $\mathrm{Cr}^{3+}$ in aqueous media. Dyes Pigments. 2013;97(1):148-54.

34. Feng E, Fan C, Wang N, Liu G, Pu S. A highly selective diarylethene chemosensor for colorimetric detection of $\mathrm{CN}-$ and fluorescent relaydetection of $\mathrm{Al}^{3+} / \mathrm{Cr}^{3+}$. Dyes Pigments. 2018;151:22-7.

35. Fan $C$, Huang $X$, Black CA, Shen $X$, Qi J, Yi Y, Lu Z, Nie Y, Sun G. A fastresponse, fluorescent 'turn-on'chemosensor for selective detection of $\mathrm{Cr}^{3+}$ RSC Adv. 2015:5(86):70302-8

36. Hu Z-Q, Lin C-S, Wang X-M, Ding L, Cui C-L, Liu S-F, Lu HY. Highly sensitive and selective turn-on fluorescent chemosensor for $\mathrm{Pb}^{2+}$ and $\mathrm{Hg}^{2+}$ based on a rhodamine-phenylurea conjugate. Chem Commun. 2010;46(21):3765-7.

37. Khairnar N, Tayade K, Sahoo SK, Bondhopadhyay B, Basu A, Singh J, Singh N, Gite $V$, Kuwar A. A highly selective fluorescent 'turn-on'chemosensor for $\mathrm{Zn}^{2+}$ based on a benzothiazole conjugate: their applicability in live cell imaging and use of the resultant complex as a secondary sensor of $\mathrm{CN}-$. Dalton Trans. 2015;44(5):2097-102.

38. Gupta VK, Singh AK, Kumawat LK, Mergu N. An easily accessible switch-on optical chemosensor for the detection of noxious metal ions Ni (II), Zn (II), Fe (III) and UO2 (II). Sensors Actuators B Chem. 2016;222:468-82.

39. Sarkar D, Pramanik A, Jana S, Karmakar P, Mondal TK. Quinoline based reversible fluorescent 'turn-on'chemosensor for the selective detection of $\mathrm{Zn}^{2+}$ : application in living cell imaging and as INHIBIT logic gate. Sensors Actuators B Chem. 2015;209:138-46.

40. Singha S, Kim D, Seo H, Cho SW, Ahn KH. Fluorescence sensing systems for gold and silver species. Chem Soc Rev. 2015;44(13):4367-99.

41. Sun W, Guo S, Hu C, Fan J, Peng X. Recent development of chemosensors based on cyanine platforms. Chem Rev. 2016;116(14):7768-817.

42. Iyoshi S, Taki M, Yamamoto Y. Rosamine-based fluorescent chemosensor for selective detection of silver (I) in an aqueous solution. Inorg Chem. 2008; 47(10):3946-8

43. Velmurugan K, Raman A, Easwaramoorthi S, Nandhakumar R. Pyrene pyridineconjugate as Ag selective fluorescent chemosensor. RSC Adv. 2014;4(67):35284-9.

44. Zhang B, Sun J, Bi C, Yin G, Pu L, Shi Y, Sheng L. A highly selective ratiometric fluorescent chemosensor for $\mathrm{Ag}^{+}$based on a rhodanineacetic acid-pyrene derivative. New J Chem. 2011;35(4):849-53.

45. Li C-Y, XU F, Li Y-F. A fluorescent chemosensor for silver ions based on porphyrin compound with high selectivity. Spectrochim Acta A Mol Biomol Spectrosc. 2010;76(2):197-201.

46. Zheng $H$, Yan M, Fan X-X, Sun D, Yang S-Y, Yang L-J, Li J-D, Jiang Y-B. A heptamethine cyanine-based colorimetric and ratiometric fluorescent chemosensor for the selective detection of $\mathrm{Ag}^{+}$in an aqueous medium. Chem Commun. 2012:48(16):2243-5.

47. Li C-Y, Kong X-F, Li Y-F, Zou C-X, Liu D, Zhu W-G. Ratiometric and colorimetric fluorescent chemosensor for $\mathrm{Ag}^{+}$based on tricarbocyanine. Dyes Pigments. 2013;99(3):903-7. 
48. Zheng H, Zhang X-J, Cai X, Bian Q-N, Yan M, Wu G-H, Lai X-W, Jiang Y-B, Ratiometric fluorescent chemosensor for $\mathrm{Hg}^{2+}$ based on heptamethine cyanine containing a thymine moiety. Org Lett. 2012;14(8):1986-9.

49. Zheng $\mathrm{S}$, Lingyue $\mathrm{G}$, Ong MJH, Jacquemin D, Romieu A, Richard J-A, Srinivasan R. Divergent synthesis of 5', 7'-difluorinated dihydroxanthenehemicyanine fused near-infrared fluorophores. Org Biomol Chem. 2019; 17(17):4291-300

50. Liu S-Y, Xiong H, Yang J-Q, Yang S-H, Li Y, Yang W-C, Yang G-F. Discovery of butyrylcholinesterase-activated near-infrared fluorogenic probe for live-cell and in vivo imaging. ACS Sens. 2018;3(10):2118-28.

51. Qin H, Ren J, Wang J, Wang E. G-quadruplex facilitated turn-off fluorescent chemosensor for selective detection of cupric ion. Chem Commun (Camb). 2010;46(39):7385-7.

52. Fang G, Bi X. Silver-catalysed reactions of alkynes: recent advances. Chem Soc Rev. 2015:44(22):8124-73.

53. Takahashi Y, Kasai H, Nakanishi H, Suzuki TM. Test strips for heavy-metal ions fabricated from nanosized dye compounds. Angew Chem Int Ed. 2006;45(6): 913-6.

54. Yang G, Meng X, Fang S, Duan H, Wang L, Wang Z. A highly selective colorimetric fluorescent probe for detection of $\mathrm{Hg}^{2+}$ and its application on test strips. RSC Adv. 2019;9(15):8529-36.

\section{Publisher's Note}

Springer Nature remains neutral with regard to jurisdictional claims in published maps and institutional affiliations.

\section{Submit your manuscript to a SpringerOpen ${ }^{\circ}$ journal and benefit from:}

- Convenient online submission

- Rigorous peer review

- Open access: articles freely available online

High visibility within the field

- Retaining the copyright to your article

Submit your next manuscript at $\boldsymbol{\nabla}$ springeropen.com 